\title{
ENKRIPTOR-DEKRIPTOR ISI E-MAIL BERBASIS ANDROID DENGAN ALGORITMA BLOWFISH
}

\author{
Yonathan Gani Panjaitan \\ Program Studi Teknik Informatika, Fakultas Ilmu Komputer \\ Universitas Dian Nuswantoro \\ Email: jonathanpanjaitan49@gmail.com \\ Ajib Susanto \\ Program Studi Teknik Informatika, Fakultas Ilmu Komputer \\ Universitas Dian Nuswantoro \\ Email: ajib.susanto@dsn.dinus.ac.id \\ Wijanarto \\ Program Studi Teknik Informatika, Fakultas Ilmu Komputer \\ Universitas Dian Nuswantoro \\ Email:wijanarto@dsn.dinus.ac.id \\ Ibnu Utomo W.M \\ Program Studi Teknik Informatika, Fakultas Ilmu Komputer \\ Universitas Dian Nuswantoro \\ Email:ibnu@dsn.dinus.ac.id
}

\begin{abstract}
ABSTRAK
Perkembangan teknologi informasi yang pesat diiringi oleh perkembangan dalam hal keamanan data. Terutama informasi atau hal-hal rahasia yang orang lain tidak boleh mengetahui. Salah satu teknologi yang terus semakin berkembang adalah Email dan munculnya platform baru yang bernama Android yang digunakan pada smartphone. Email merupakan salah satu cara untuk bertukar informasi antara satu orang dengan yang lain. Kejahatan teknologi informasi terus berkembang dan dengan berbagai macam model kejahatan, sebagai contohnya adalah Sniffing. Algoritma Blowfish merupakan salah satu algoritma algoritma block cipher 64-bit block yang cukup aman untuk mengamankan data di dalam sebuah program, tidak dipatenkan, mempunyai ruang kunci yang besar dan panjangnya bermacammacam dari 32 bits sampai 448 bits serta cukup kuat keamanannya, sehingga pada bagian kuncinya tidak mudah diserang oleh pihak lain. Metode pendekatan sistem yang digunakan dalam pembangunan aplikasi adalah Extreme Programming $(X P)$ untuk menerapkan fungsi dari Enkripsi dan Dekripsi dalam versi aplikasi berbasis Android. Hasil penelitian berupa aplikasi berbasis Android yang dapat mengenkripsi sebagian atau semua isi E-mail yang dikirim dan dapat mendeskripsi kembali seperti text semula menggunakan algoritma Blowfish dengan kunci tertentu.
\end{abstract}

Kata kunci: android, email, sniffing, extreme programming, blowfish.

\begin{abstract}
The rapid development of information technology is accompanied by the development in terms of data security. Specifically, the information or secret things that other people may not know. One technology that keeps growing is E-mail and the emergence of a new platform called Android that is used on smartphones. E-mail is one way to exchange information between one person and another. Crime information technology continues to evolve and with various models of crime, for example is Sniffing. Blowfish algorithm is an algorithm algorithm block cipher 64-bit block that is safe enough to secure data within a program, not patented, has a room key and the length varying from 32 bits to 448 bits, and is strong enough security, so that the the key parts are not easily attacked by the other party. Method approach of system used in application development is the Extreme Programming (XP) to implement the functions of encryption and decryption in the version of Android-based applications. The results of this research were Android-based application that can encrypt part or all of the contents of E-mails sent and can describe again as the original text using the Blowfish algorithm with a particular key.
\end{abstract}

Keywords: android, email, sniffing, extreme programming, blowfish. 


\section{PENDAHULUAN}

Kemudahan dan kecepatan akses komunikasi dan informasi berpengaruh besar terhadap perkembangan pertukaran data dan informasi termasuk di dalamnya keamanan informasinya. Informasi akan menjadi mudah diketahui[1], diambil, dimanipulasi maupun disalahgunakan oleh berbagai pihak lain yang tidak mempunyai akses dan tidak berhak mendapatkan data dan informasi. Penerima informasi harus memverifikasi informasi yang didapat, yakin suatu informasi tersebut adalah dari pengirim atau sumber yang tepat[2], dikenal dan benar isinya. Saat ini media komunikasi yang digunakan atau dimanfaatkan semestinya merupakan media yang mudah, murah, terjangkau dan digunakan oleh kebanyakan orang. Salah satu yang popular untuk berkomunikasi adalah E-mail. Beberapa tahun terakhir ini muncul sebuah platform baru yang merupakan teknologi baru, salah satunya adalah telepon seluler (ponsel). Salah satunya yang paling populer sekarang ini adalah ponsel smartphone berplatform android yang mempunyai beberapa fungsi seperti e-mail, social media, video streaming, multimedia, transfer data, multiplayer games dan lain-lain. Namun, akibat dari berkembangnya jumlah pengguna fasilitas $E$ mail di android yang digunakan sebagai alat penyimpan data dan informasi, baik informasi pribadi ataupun informasi bisnis perusahaan, tidak sedikit pengguna yang berbuat tidak baik untuk mencari tahu bahkan mengubah-ubah data yang disimpan oleh pengguna tersebut. Apalagi diketahui sekarang bahwa Android merupakan platform open source yang dikatakan masih baru teknologinya dan juga masih sedikitnya pengamanan di ponsel Android[3].

Contoh kasus tahun 2012 dalam hal penyadapan isi dari E-mail adalah Skandal Penyadapan Kedua Dalam Kisruh Bumi Plc yang dimana dalam berita ini Samin Tan, chairman Bumi Plc merasa aneh dengan sebuah E-mail yang dikirimkan kepada dirinya yang berisi bahwa situs Wikipedia membutuhkan korespondensi untuk menerbitkan artikel tentang Samin Tan. Ternyata E-mail tersebut berisi malware yang berhasil mencuri semua isi E-mail dari Samin Tan dan membobol info-info penting mengenai Bumi Plc[4].

Blowfish[2][5][6] merupakan salah satu algoritma block cipher 64-bit block yang tidak dipatenkan mempunyai ruang kunci yang besar dan panjangnya bermacam-macam dari 32 bits sampai 448 bits serta cukup kuat keamanannya, sehingga pada bagian kuncinya tidak mudah diserang oleh pihak lain. Hasil penelitian Saikumar Manku dan K. Vasant[7], algoritma Blowfish menyediakan keamanan yang kuat sehingga tidak ada satu diantara pengiriman dan penerimaan data di hack. Begitu juga hasil penelitian Manju Suresh dan Neema M.[8] untuk keamanan transmisi di internet dari semua algoritma kriptografi, algoritma Blowfish adalah terbaik dalam hal waktu eksekusi, penggunaan memori, throughput, konsumsi daya, dan keamanan[9] dengan demikian cocok untuk Internet of Things (IOT).

Sistem kriptografi dapat dikatakan baik terletak di kerahasiaan kunci, bukan terletak pada kerahasiaan suatu algoritma yang digunakan. Blowfish jika diimplementasikan dengan strategi yang tepat dapat lebih optimal, dapat dijalankan dimemori kurang dari 5 (lima) KB dan kesederhanaan pada proses algoritmanya. Sehingga untuk menjamin keamanan pengiriman informasi perlu dibangun aplikasi berbasis android untuk pengguna smartphone yang dapat digunakan untuk mengamankan data atau informasi sebagian maupun keseluruhan text (isi pesan) yang dikirim melalui media E-mail dengan menggunakan algoritma Blowfish dengan membuat kunci tertentu.

Pembangunan enkriptor-dekriptor ini dilakukan dengan menggunakan dan menerapkan fungsi Algoritma Blowfish yang dikerjakan dengan metode pendekatan Extreme Programming[10][11] sehingga dihasilkan beberapa versi kecil aplikasi android yang terus ditingkatkan hingga mencapai tujuan optimal yaitu menerapkan Algoritma Blowfish yang bisa mengamankan/merahasiakan isi E-mail yang dilakukan langsung dalam aplikasi berbasis Android dengan spesifikasi minimum Android 2.2.

\section{METODE PENELITIAN}

Metode pendekatan sistem berbasis obyek yaitu Extreme Programming $(X P)[10][11]$ dengan pemodelam Unified Modeling Language (UML) menekankan pada interaksi antar customer dengan developer. Aplikasi dikerjakan sesuai kesepakatan antar customer dan developer dalam suatu iterasi yang pada tiap iterasinya dihasilkan suatu unit aplikasi siap pakai (ditingkatkan fungsinya pada iterasi selanjutnya, terus diperbaiki sampai tujuan penelitian sepenuhnya dicapai). 


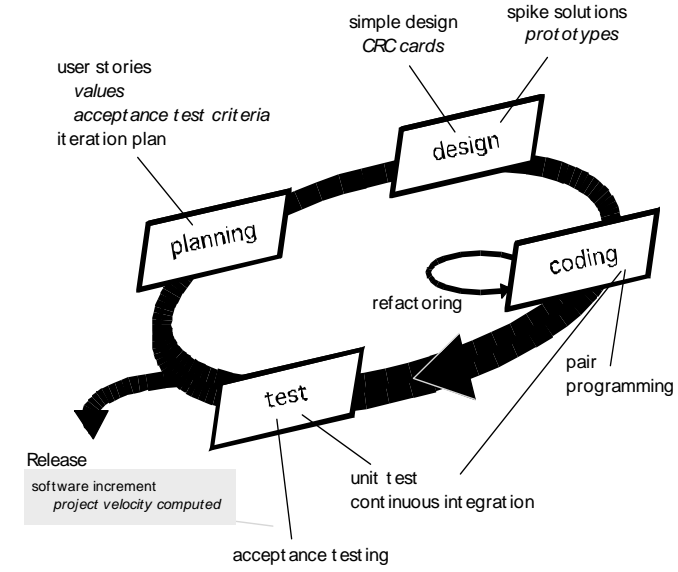

Gambar 1. Fase Extreme Programming (XP)[10]

Fase pengembangan sistem dengan XP :

a. Release Planning (perencanaan penelitian secara utuh)

b. Iteration (iterasi penelitian, terdapat perencanaan, pengerjaan, serta pengujian di tiap unit aplikasi yang dihasilkan)

c. Acceptance Test (pengujian secara menyeluruh untuk versi terakhir aplikasi)

d. Small Release (perilisan aplikasi)

\section{HASIL DAN PEMBAHASAN}

\subsection{Arsitektur Sistem}

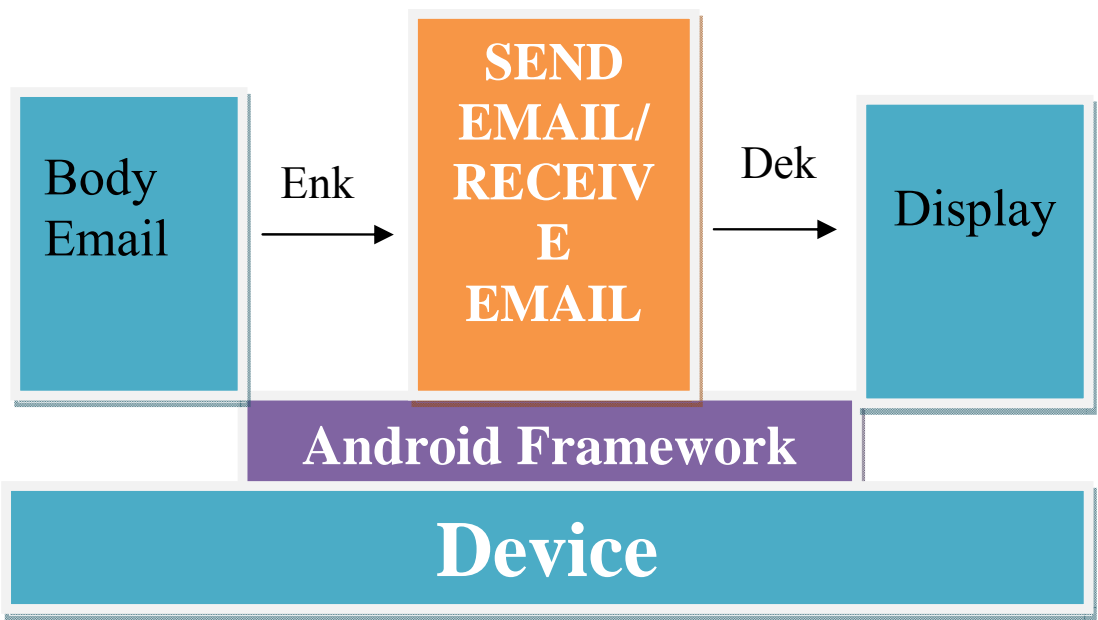

Gambar 2. Desain Arsitektur Aplikasi

Gambar 2 menunjukkan beberapa komponen yang terlibat dalam sistem, yaitu isi email (body email) pada perangkat (device) Android, fungsi Enkripsi (Enk), Send Email/Receive Email, Dekripsi (Dek) beroperasi dalam lingkup sistem Android (Android Framework). Masukkan ke aplikasi adalah Body Email yang diketik oleh user, kemudian aplikasi mengubah isi dari body email tersebut (dienkrip) menjadi bentuk atau hasil dari algoritma Blowfish yang nantinya hasil tersebut dikirimkan menjadi sebuah E-mail. Kemudian jika mendapatkan balasan atau Receive E-mail yang mana harus mengakses salah satu provider E-mail, akan diubah (didekrip) kembali menjadi plainteks atau teks biasa yang dapat ditampilkan dan terbaca. 


\subsection{Penerapan Algoritma Blowfish pada Aplikasi}

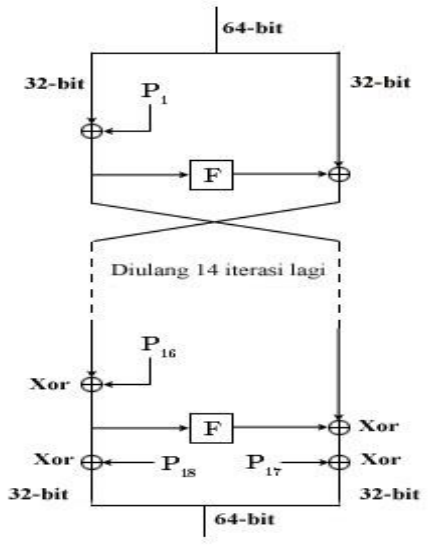

Gambar 3. Iterasi Algoritma Blowfish

Gambar 3 menggambarkan di dalam Blowfish ada penghitungan iterasi subkunci sebanyak 521 iterasi[12]. Langkah-langkahnya terdiri dari :

1) Inilialisasi P-array, selanjutnya 4 (empat) S-box secara berturut-turut dengan nilai String yang tetap. Nilai String berisi digit hexadesimal dari Pi.

2) $P_{1}$ di XOR dengan 32-bit pertama dari kunci, $P_{2}$ di XOR dengan 32-bit kedua dari kunci dan seterusnya untuk setiap bit dari kunci (sampai $\mathrm{P}_{18}$ ). Ulangi terhadap bit kunci sampai keseluruhan $\mathrm{P}$ array di XOR dengan bit kunci.

3) Enkripsi semua String nol menggunakan algoritma Blowfish dengan subkunci seperti pada langkah (1) dan langkah (2).

4) $\mathrm{P}_{1}$ dan $\mathrm{P}_{2}$ diganti dengan output dari langkah (3).

5) Enkripsi output dari langkah (3) dengan algoritma Blowfish menggunakan subkunci yang sudah dimodifikasi sebelumnya.

6) $\mathrm{P}_{3}$ dan $\mathrm{P}_{4}$ diganti dengan output dari langkah (5).

7) Lanjutkan proses, ganti keseluruhan elemen dari P-array, selanjutnya keseluruhan 4 (empat) S-box secara berturut-turut, dengan output yang berubah secara kontinyu dari algoritma Blowfish.

Langkah-langkah di atas diwakili oleh fungsi setKey(), yang mana bagian ini merupakan bagian pengubahan subkey, dan bagian ini berubah seiring key inputan yang digunakan.

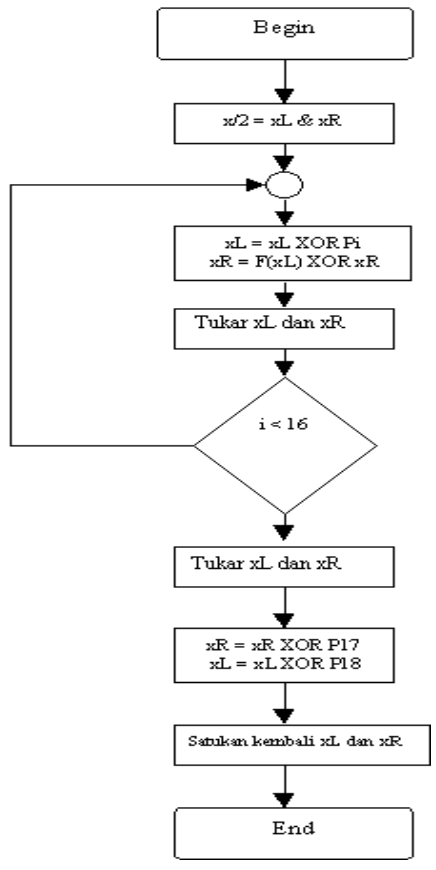

Gambar 4. Flowchart Blowfish 
Langkah-langkah algoritma Blowfish dalam aplikasi enkriptor-dekriptor yang ditunjukkan pada gambar 4 adalah sebagai berikut :

1) User diminta untuk memasukkan inputan text pada body mail pada aplikasi ini.

Pada code program dimulai pada fungsi getInit(), dimana fungsi ini yang menangkap karakter yang diinputkan user. Kemudian mengubahnya dalam bentuk String.

2) Jika user memasukkan inputan kurang dari 64 bit maka secara otomatis dilakukan penambahan bit oleh algoritma Blowfish.

3) Jika sudah memenuhi kriteria 64 bit data maka blowfish engine akan mulai menginisiasi perputaran atau iterasinya yaitu sebanyak 16 kali perputaran[6].

Pada code program, disinilah dimulai fungsi run(). Dimana fungsi ini mengubah string inputan tadi menjadi dalam bentuk byte.

4) Data 64 bit yang sudah diinputkan oleh user akan dibagi 2 (anggap saja $x l$ dan xr), menjadi masingmasing 32 bit yang kemudian diproses dengan menggunakan perhitungan XOR.

Pada code program, engine blowfish (blowfishengine.java) dipanggil oleh fungsi run(), yang mana nantinya engine ini akan mulai bergerak dan melakukan proses iterasi. Pada saat ini jika user ingin mengenkrip data maka run() akan memanggil fungsi di blowfishengine.java yaitu tryEncryptBlock() yang merupakan implementasi dari fungsi encryptBlock(). Begitupun sebaliknya jika melakukan dekripsi maka yang dipanggil adalah tryDecryptBlock() yang merupakan implementasi dari fungsi decryptBlock().

5) Jika sudah sampai ke iterasi ke 16, maka hasil perhitungan $\mathrm{xl}$ dan $\mathrm{xr}$ ditukar kembali dan di XORkan dengan bagian 17 dan 18.

6) Kembali ditukar dan jadilah sebuah cipherteks yang berisi 64 bit data, sesuai dengan inputan yang diberikan user.

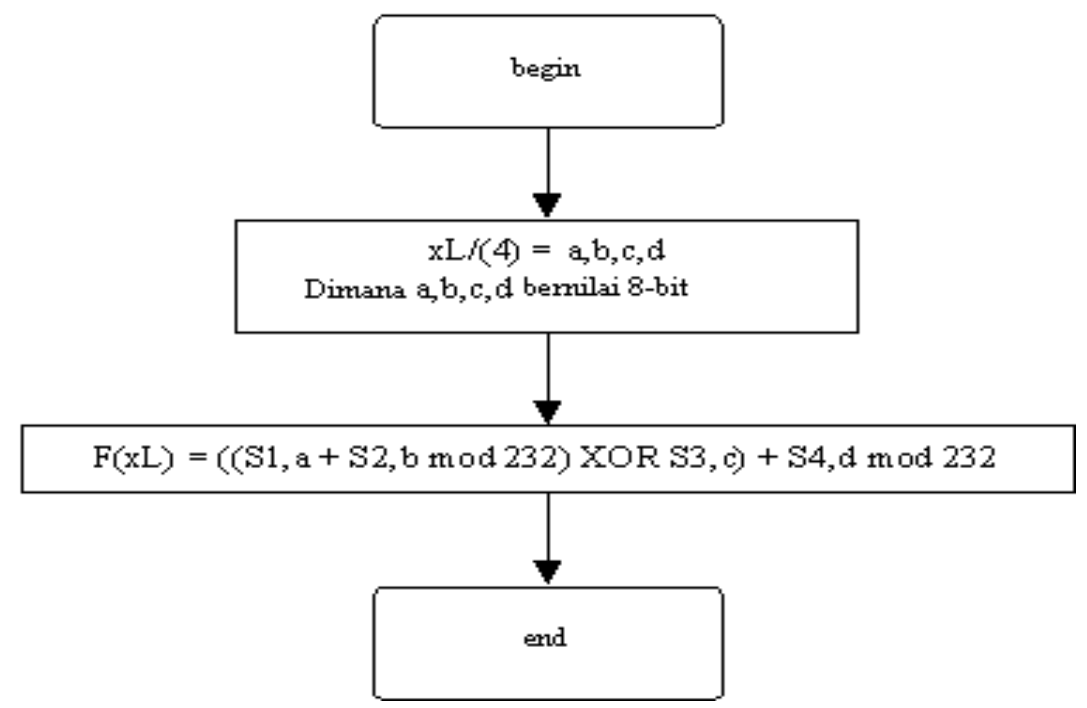

\section{Gambar 5. Flowchart Fungsi F[13]}

Gambar 5 menunjukkan fungsi $\mathrm{F}$ yang merupakan salah satu bagian penghitungan dari algoritma Blowfish. Penjelasannya adalah sebagai berikut :

1) Salah satu pembagian dari data 64 bit (xl) ini akan dioperasikan dengan hasil dari fungsi $\mathrm{F}$ ini.

2) Kemudian setelah mendapatkan hasil dari fungsi $F$ ini maka hasilnya yaitu $F(x l)$ di XOR kan oleh xr.

Kedua langkah ini diwakili oleh fungsi $\mathrm{F}($ ) dengan S-box yang sudah di-array-kan. 


\subsection{Perancangan Aplikasi}

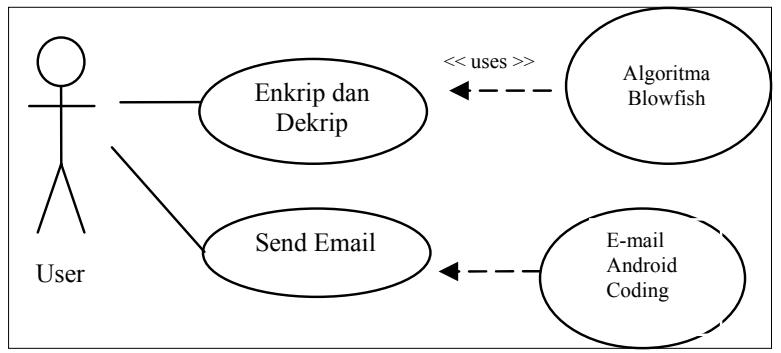

Gambar 6. Diagram Use Case

Gambar 6 menggambarkan pengguna aplikasi ini dapat memilih apakah user ingin mengenkripkan isi dari E-mail ataupun tidak. Namun user bisa mengirimkan E-mail melalui aplikasi tersebut

\subsection{Implementasi Enkriptor-Dekriptor}

Implementasi sistem berupa aplikasi android yang terdiri dari kelas utama sebagai halaman utama serta berfungsi menghubungkan semua fungsi dalam aplikasi ini. Dimana main.java menjadi halaman utama untuk memanggil EnkripsiAktivitas.java dan DekripsiAktivitas.java yang berinti pada BlowfishEngine.java. Berikut merupakan hasil implementasi:

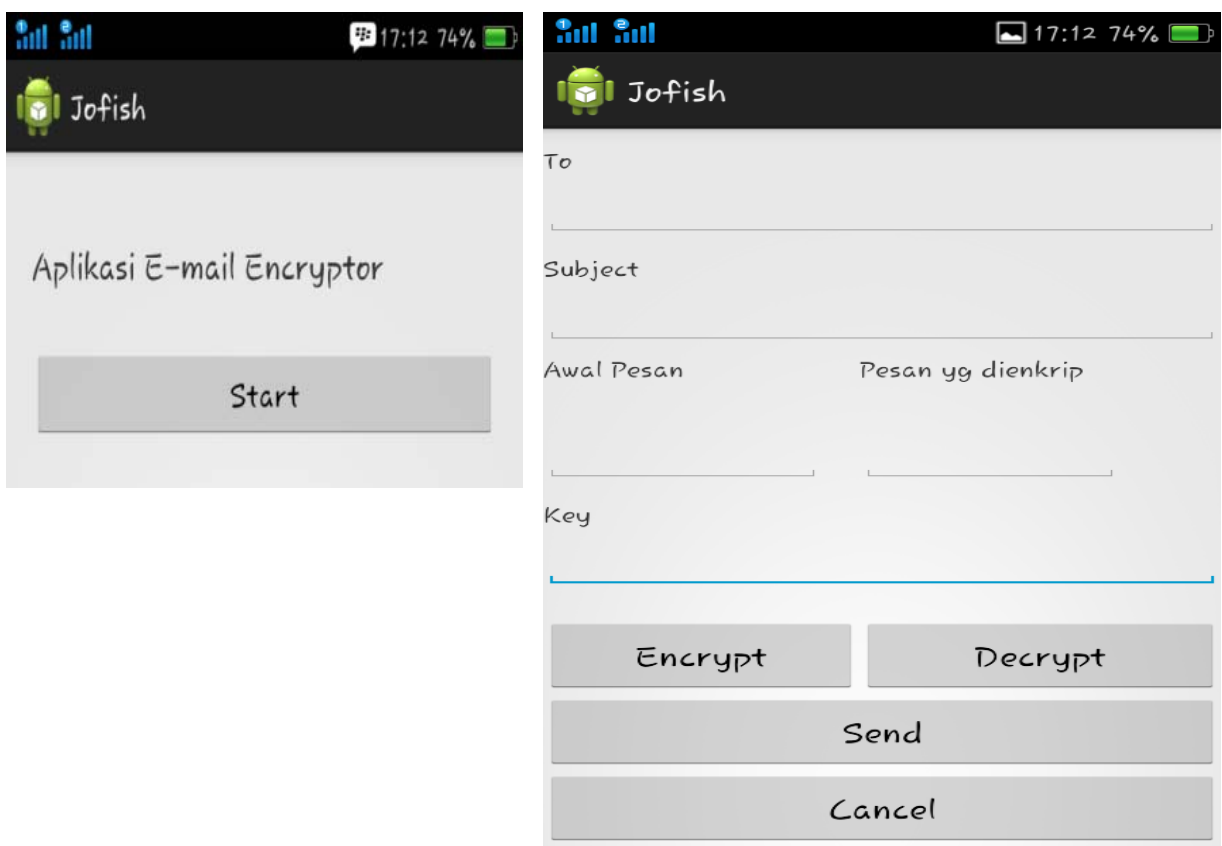

Gambar 7. Tampilan Awal dan Inti Aplikasi (Field Kosong)

Gambar 7 memperlihatkan tampilan awal aplikasi yang terdiri dari satu tombol (start) untuk memulai membuka aplikasi. Kemudian ketika sudah memilih aktivasi aplikasi maka aplikasi ini akan dimulai dengan susunan di gambar sebelahnya. Dimana user bisa memilih apakah menggunakan sistem enkripsi/dekripsinya. 


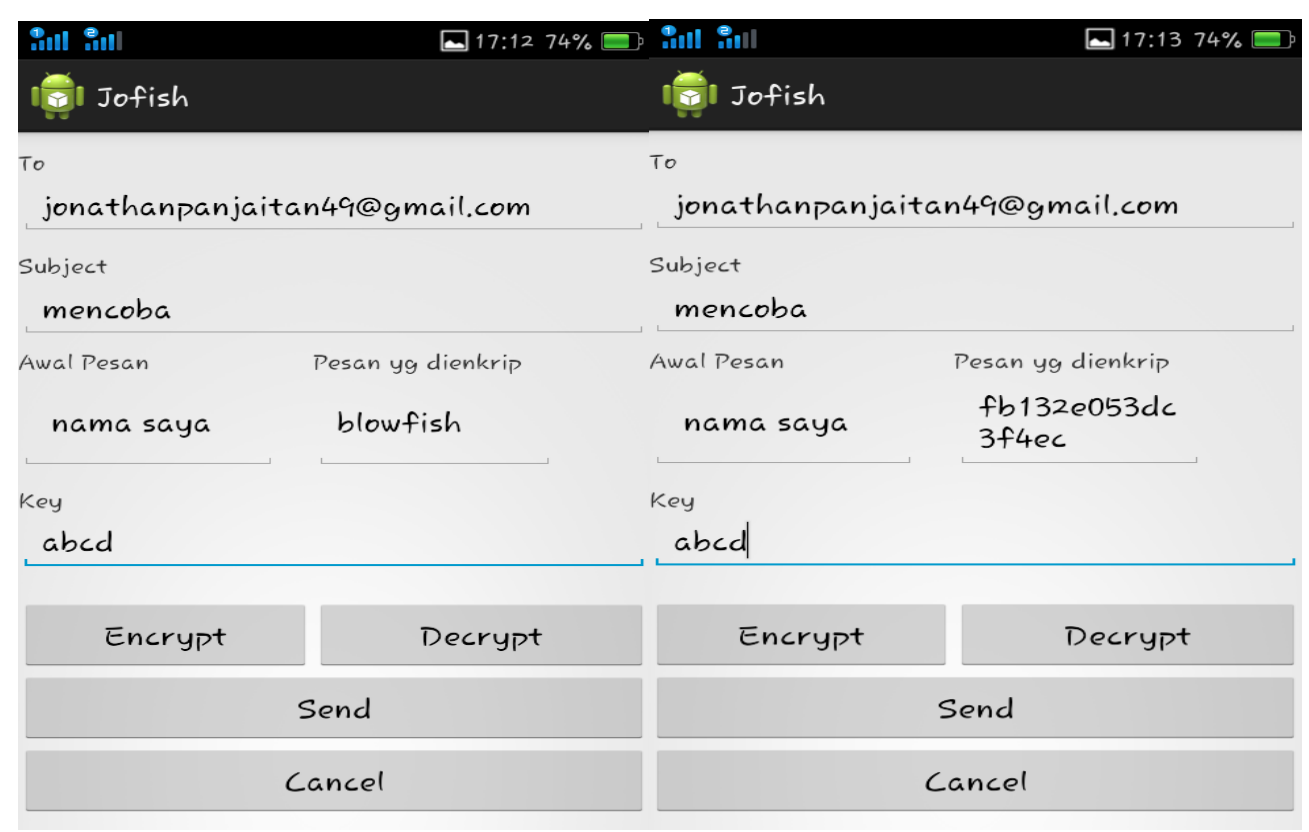

Gambar 8. Tampilan Pengisian Field dan Hasil Enkripsi

Pada Gambar 8 ini memperlihatkan user bisa memasukkan bagian-bagian dari sebuah E-mail seperti alamat Email, subject, isi pesan yang terbagi 2 (dua) menjadi awal pesan (tidak bisa dienkripsi/dekripsi), yang kedua pesan yang dienkripsi. Sehingga pesan nanti tidak semua harus dienkripsi (kembali pada keinginan user)

\section{KESIMPULAN}

a. Fungsi Algoritma Blowfish dapat diterapkan dengan baik pada aplikasi Android tanpa bersandar pada fungsi cipher pada pustaka android API.

b. Pengenkripsian dan pendekripsian pesan juga berjalan dengan baik, begitupun dengan pengiriman E-mail dari aplikasi ini.

c. Aplikasi ini dapat digunakan dengan Android versi Gingerbread ke atas, namun jika ada yang menggunakan versi di bawahnya, tetap bisa digunakan.

\section{DAFTAR PUSTAKA}

[1] Rahman, C., Nadhori, I.U., Fathoni, K. 2009. Studi Dan Implementasi Algoritma Blowfish Untuk Enkripsi Email. ITS : Surabaya.

[2] Sitinjak, S., Fauziah, Y., Juwairiah. 2010. Aplikasi Kriptografi File Menggunakan Algoritma Blowfish. UPN "Veteran": Yogyakarta.

[3] Taufan A., Y., Winarno, I., Fathoni, K. . Enkripsi Email Dengan Menggunakan Metode Elgamal Pada Perangkat Mobile. ITS : Surabaya

[4] Skandal Penyadapan Kalam Kisruh Bumi PLC. https://harcipto.wordpress.com/2012/12/12/skandal-penyadapan-kedua-dalam-kisruh-bumi-plc/. Diakses 06 Maret 2017 Jam 10:26.

[5] Bruce Schneier. The Blowfish Encryption Algorithm. https:/www.schneier.com/academic/blowfish/. Diakses 06 Maret 2017 Jam 10:15.

[6] Schneier, Bruce. 1995. The Blowfish Encryption Algorithm -- One Year Later. Dr. Dobb's Journal. https://www.schneier.com/academic/archives/1995/09/the_blowfish_encrypt.html. Diakses pada 06 Maret 2017 Jam 10:35.

[7] Saikumar Manku, K. Vasanth, 2015, Blowfish Encryption Algorithm for Information Security, ARPN Journal Engineering and Applied Science, Asian Research Publishing Network (ARPN).

[8] Manju Suresh, Neema M, 2016, Hardware Implementation of Blowfish Algorithm for The Secure DataTransmission in Internet of Things, Global Colloquium in Recent Advancement and Effectual Researches in Engineering, Science and Technology (RAEREST 2016), Procedia Technology. 
[9] Chaitali Haldankar, Sonia Kulwelkar, 2014, Implementation of AES and Blowfish Algorithm, IJRET: International Journal of Research in Engineering and Technology.

[10] Pressman, Roger S., 2010, Software Engineering : a practitioner's approach Seventh Edition., New York, The McGraw - Hill Companies, Inc..

[11] Extreme Programming. http://www.extremeprogramming.org. Diakses pada 06 Maret 2017 Jam $10: 20$.

[12] Tri Andriyanto, D.L. Crispina Pardede. 2008. Studi dan Perbandingan Algoritma Idea dan Algoritma Blowfish, Gunadarma : Jakarta

[13] Ema Utami, Shanty Erikawaty A.T, 2010, Penerapan Algoritma Blowfish Untuk Membuat Sebuah Model Kriptosistem Algoritma Dan Menganalisis Kinerja Algoritma Blowfish Dengan Simulasi Data Terbatas, Jurnal DASI : Yogyakarta. 